\title{
The Transformational Path Ahead: Competency-Based Medical Education in Family Medicine
}

\author{
Eric S. Holmboe, MD
}

\begin{abstract}
Competency-based medical education (CBME) is an outcomesbased approach that has taken root in residency training nationally and internationally. CBME explicitly places the patient, family, and community at the center of training with the primary goals of concomitantly improving both educational and clinical outcomes. Family medicine, as the foundational primary care discipline, has always embraced the importance of linking training with health system needs and performance since its inception. While CBME is no longer a new concept, full implementation of this outcomes-based approach has been daunting and challenging. Gaps in the effectiveness, safety, equity, efficiency, timeliness, and patient/family centeredness of health and health care in the United States continue to be persistent and pernicious. These gaps summon family medicine and the entire graduate medical education system to take stock of its current state and to examine how more fully embracing an outcomes-based educational approach can help to close these gaps.

This article provides a brief history of the CBME movement, and more importantly, its key underlying educational principles and science. I will explore the key inflection points of progress, including identifying core CBME components, introduction of competency Milestones, experimental pilots of time variable training, advancements in mastery-based learning, and advances in work-based assessment, within the context of family medicine. I will conclude with suggestions for accelerating the adoption and implementation of CBME within family medicine residency training.
\end{abstract}

(Fam Med. 2021;53(7):583-9.)

doi: 10.22454/FamMed.2021.296914

Published Online First May 17, 2021

$\mathbf{T}$ he origins of competency-based medical education (CBME) began soon after family medicine became a recognized medical specialty. In 1978 the World Health Organization (WHO) published a white paper entitled Competency-based Curriculum Development in Medical Education. ${ }^{1}$ This report was heavily influenced by the need for medical education to better meet public health needs in both developed and developing nations. The authors proposed three important principles of a competency-based curriculum. First and foremost, the curriculum had to be organized around the competencies (ie, abilities) that were needed for practice within a specified setting. Second, the design of the curriculum and instruction should enable all learners to master the basic performance competencies of the profession and specialty discipline for the setting of future practice. Finally, they argued education should be viewed as an experiment where both the "processes and techniques" that are used to create the learning should be philosophically treated as hypotheses that are constantly tested and refined.

McGaghie and colleagues importantly argued that mastery-based learning should be the underlying educational principle for all of medical education. This requires meaningful entry-level assessment, stepwise instruction, flexible time scheduling, and frequent assessment that facilitates "cumulative learning along a continuum of increasing medical sophistication." Ultimately,

the intended output of a competency-based program is a health professional who can practice medicine at a defined level proficiency in accord with local conditions to meet local needs. ${ }^{1}$

I suspect these original tenets will resonate deeply with educators in family medicine, a specialty discipline firmly grounded in public health and focused on community needs since its inception. Unfortunately, these early CBME principles did not take firm root in undergraduate or graduate medical education at that time, due to several factors.

From the Accreditation Council for Graduate Medical Education, Chicago, IL. 
One major factor was, and still is, inertia for change in medical education. ${ }^{2}$ Another is the continued misalignment between appropriate service and educational needs. Health care is a service profession, but learners should be performing services best aligned with their professional development needs and patient care. ${ }^{3}$ Finally, high-quality assessments, especially work-based assessments, were quite limited in 1978, and impeded progress in assessing competencies beyond medical knowledge.

The next catalyst for educational change in the United States began in the late 1980s with growing concerns around the quality and safety of health care. This concern culminated in two Institute of Medicine (IOM, now the National Academy of Medicine) reports, To Err is Human (2000) and Crossing the Quality Chasm (2001).,5 The To Err is Human report estimated that 98,000 Americans died each year from medical errors; a sobering number a more recent study concluded was probably substantially higher. ${ }^{6}$ McGlynn and colleagues in their landmark study found that Americans were, on average, only receiving $54 \%$ of recommended clinical care practices. ${ }^{7}$ Recognition of health care quality and safety problems helped rekindle interest in outcomes-based medical education in several countries, including the United States. In 1999, a joint Accreditation Council for Graduate Medical Education (ACGME) and American Board of Medical Specialties effort led by Dr Paul Batalden produced the general competency framework. ${ }^{8}$ In July 2001, the ACGME launched the Outcome Project to guide the transformation of graduate medical education (GME) using the six new general competency domains to support implementation of an outcomesbased medical education system. ${ }^{8}$

A major goal of the Outcome Project was to move away from an overreliance on proxies such as amount of time spent training, completion of a required number of curricular rotations based on medical content and settings, and high-stakes examinations. Yet the predominant model of GME still relies substantially on "dwell time" as a proxy for competence. David Hodges, $\mathrm{MD}, \mathrm{PhD}$, used the metaphor of leaving a tea-bag in just long enough until a masterful cup of tea is produced. ${ }^{9}$ This timebased model erroneously assumes everyone learns at the same pace, in the same way, and ends up at the same place. No one argues that a certain amount of experience and time is essential to produce a proficient family physician prepared to meet community needs, as envisioned by the WHO report over 40 years ago. However, not enough attention has been focused on how time and experience is used to support successful educational outcomes.

Competency-based medical education (CBME) has taken root as an approach because it places the patient, family, and community more explicitly at the center of training with a primary goal of increasing the effectiveness of the medical education system. ${ }^{10} \mathrm{CBME}$ recognizes the intimate relationship between clinical and educational outcomes, and calls for greater accountability of the medical education system. Specifically, summative entrustment decisions must be grounded in a robust competency-based curriculum and valid assessment. The six aims from the original Institute of Medicine report apply equally to medical education and undergird CBME: training should be patient-centered, safe, effective, equitable, timely, and efficient. ${ }^{5} \mathrm{CBME}$ is best viewed as a complex intervention with multiple interacting and interdependent components, a long journey that began over 20 years ago and will continue into the foreseeable future.

\section{Early Stumbles and Inflection Points of Progress}

Early experience with implementation of the Outcome Project was arduous as programs struggled to make sense of the competencies, incorporate them into new curricula, and institute new assessment approaches. It was, and continues to be, difficult to move away from a heavy reliance on a rotational curricular model for specialties like family medicine. Complicating the shift to CBME has been the ongoing intense changes in health care delivery since 2001, and medical education across the continuum has struggled to keep pace and appropriately adjust. ${ }^{11}$ However, the last 10 years has seen some meaningful progress on multiple fronts, including promising experiments in CBME. Key inflection points of progress include:

- Refinement of the definition and components of CBME;

- Introduction of Milestones;

- Experimental pilots of time-variable training;

- Advancement of mastery-based learning models; and

- Advances in assessment.

Let's briefly review each of these in the context of family medicine as it grapples with its future.

\section{Refinement of the Definition and Components of CBME}

In 2010 , an international group of medical educators updated and refined the definition of CBME:

an approach to preparing physicians for practice that is fundamentally oriented to graduate outcome abilities and organized around competencies derived from an analysis of societal and patient needs. It de-emphasizes time-based training and promises greater accountability, flexibility and learnercenteredness. ${ }^{12}$

More recently, van Melle et al performed a robust literature review followed by an international Delphi process to define and delineate the core components of CBME, providing additional guidance for developing CBME programs (Table 1). ${ }^{13}$

There are several important observations about the core components framework. First, CBME is grounded in a rich amalgam of multiple pedagogical theories and 
Table 1: Van Melle Framework for Competency-Based Medical Education ${ }^{1}$

\begin{tabular}{|c|c|}
\hline Component & Description \\
\hline $\begin{array}{l}\text { An outcomes-based } \\
\text { competency framework }\end{array}$ & $\begin{array}{l}\text { - Desired outcomes of training are identified based on societal needs. } \\
\text { - Outcomes are paramount so that the graduate functions as an effective health } \\
\text { professional. }\end{array}$ \\
\hline $\begin{array}{l}\text { Progressive sequencing of } \\
\text { competencies }\end{array}$ & $\begin{array}{l}\text { - In CBME, competencies and their developmental markers must be explicitly sequenced } \\
\text { to support learner progression from novice to master clinician. } \\
\text { - Sequencing must consider that some competencies form building blocks for the } \\
\text { development of further competence. } \\
\text { - Progression is not always a smooth, predictable curve. }\end{array}$ \\
\hline $\begin{array}{l}\text { Learning experiences } \\
\text { tailored to competencies } \\
\text { in CBME }\end{array}$ & $\begin{array}{l}\text { - Time is a resource, not a driver or criterion. } \\
\text { - Learning experiences should be sequenced in a way that supports the progression of } \\
\text { competence. } \\
\text { - There must be flexibility to accommodate variation in individual learner progression. } \\
\text { - Learning experiences should resemble the practice environment. } \\
\text { - Learning experiences should be carefully selected to enable acquisition of one or many } \\
\text { - Most learning experiences should be tied to an essential graduate ability. }\end{array}$ \\
\hline $\begin{array}{l}\text { Teaching tailored } \\
\text { to competencies }\end{array}$ & $\begin{array}{l}\text { - Clinical teaching emphasizes learning through experience and application, not just } \\
\text { knowledge acquisition. } \\
\text { - Teachers use coaching techniques to diagnose a learner in clinical situations and give } \\
\text { actionable feedback. } \\
\text { - Teaching is responsive to individual learner needs. } \\
\text { - Learners are actively engaged in determining their learning needs. } \\
\text { - Teachers and learners coproduce learning. }\end{array}$ \\
\hline $\begin{array}{l}\text { Programmatic assessment } \\
\text { (ie, program of assessment) }\end{array}$ & $\begin{array}{l}\text { - There are multiple points and methods for data collection. } \\
\text { - Methods for data collection match the quality of the competency being assessed. } \\
\text { - Emphasis is on workplace-based assessment. } \\
\text { - Emphasis is on providing personalized, timely, meaningful feedback. } \\
\text { - Progression is based on entrustment. } \\
\text { - There is a robust system for decision-making. } \\
\text { - Good assessment requires attention to issues of implicit and explicit bias that can } \\
\text { adversely affect the assessment process. }\end{array}$ \\
\hline
\end{tabular}

${ }^{1}$ Van Melle E, Frank JR, Holmboe ES, Dagnone D, Stockley D, Sherbino J; International Competency-based Medical Education Collaborators. A core components framework for evaluating implementation of competency-based medical education programs. Acad Med. 2019;94(7):1002-1009.

Abbreviation: CBME, competency-based medical education.

approaches. While we unquestionably need more research, innovation, and experimentation, CBME is an evidence-informed approach utilizing lessons from multiple research disciplines and fields. ${ }^{13}$ Second, the core components do not represent the totality of a GME program. Neither the six general competencies nor the five core components were designed to represent all the complexity of a discipline. There is still a deep need for the experience, wisdom, and expertise of local health care faculty. CBME should always be philosophically viewed using a "bothand" lens that combines meaningful standardization where appropriate, and the flexibility and adaptability needed. ${ }^{14}$ Family medicine may be unique in this regard given the heterogenous geographic regions and scope of practice where training programs are located. Family medicine programs will need to find the right balance between appropriate standardization of content and experience and the need to meet variable local and regional health care needs. Third, these components strongly argue residency programs should treat time as a resource and not as an intervention. Experience is essential, but it must be the right type of experience combined with programmatic assessment, feedback, and coaching. ${ }^{15,16}$

Coaching is being increasingly embraced as a core educational activity and is essential to CBME. Deiorio and colleagues define an academic coach as:

a person assigned to facilitate learners achieving their fullest potential. Coaches work with learners by evaluating performance via review of objective assessments, assisting the learner to identify needs and create a plan to achieve these, and helping the learner to be accountable. Coaches help learners improve their own self-monitoring, while modeling the idea that coaching will likely benefit them throughout their career. ${ }^{17}$

In contrast to a coach, a mentor is usually a senior faculty member who serves more as guide in the learner's 
career choices and development. Advisers within training programs are typically assigned to residents to provide basic oversight, advice, advocacy, and guidance to the learner. ${ }^{17}$

Finally, residency is an intensely developmental period, a fact only implicitly acknowledged in the past. This lack of explicit attention to learning trajectories and the stages of professional development may no longer be tenable. The leaders of the Outcome Project recognized this-the stage model of professional development heavily influenced the creation of the general competencies. ${ }^{8,18}$ The intense developmental nature of residency only serves to highlight the importance of van Melle's core components and the need for longitudinal feedback and coaching. ${ }^{13}$ However, teaching, feedback, and coaching cannot be fully effective without shared mental representations of the general competencies. ${ }^{16}$

\section{Introduction of the Milestones}

Lack of a shared understanding of the competencies, especially the newer competencies of systems-based practice (SBP) and practice-based learning and improvement (PBLI), hampered early implementation efforts. After a series of pilot projects, the Milestones were formally implemented as part of accreditation for seven specialties in 2013 and for family medicine in $2014 . .^{19,20} \mathrm{In}$ 2020 , family medicine became part of an early group of core specialties to begin using Milestones version 2.0. ${ }^{21}$ The goal of the Milestones is to create developmental language (ie, narratives) that can support shared understanding of the core competencies in family medicine among faculty and residents. Milestones are specifically designed to be used as a formative, lower-stakes tool. This enables ongoing refinement and revision to meet the needs of the specialty. Family medicine has been one of the pioneers in early validity work, and a recent qualitative study in family medicine and three other specialties has found that implementation of Milestones is also a developmental, iterative, and continuous improvement process. ${ }^{22,23}$ Milestones should be viewed as a bridge to help implement outcomes-based education based on a competency framework, and can help to continually define and refine the core abilities of the specialty in alignment with ongoing changes in the health care delivery system.

\section{Experimental Pilots}

While there is a legitimate chorus of CBME criticism asking important questions, ${ }^{24}$ several important pilot projects have demonstrated implementation of time-variable CBME is possible. The University of Toronto Orthopedic residency, leveraging a mastery-based, deliberate practice approach found residents could successfully graduate earlier than the standard 5-year program..$^{25}$ More recently, the Educating Pediatricians Across the Continuum (EPAC) also found medical students enrolled in a CBME program could matriculate earlier into residency at variable time points during the fourth year of medical school..$^{26,27}$ The EPAC project particularly highlighted the importance of empowering medical students in their own learning and assessment and the need for longitudinal relationships with faculty, elements well-suited for family medicine training. Finally, Queens University in Canada implemented time-variable residency programs for all its specialties in 2017. While data gathering on the experience with this new residency design is ongoing, the Queens University team published their initial experience with early implementation, highlighting the iterative, developmental nature and the need for flexibility and adaptation along the journey. ${ }^{28}$ Finally, the Macy Foundation published the results of a summit highlighting the potential of time-variable training from both an effectiveness and efficiency perspective, noting training for some learners should be extended beyond traditional norms. ${ }^{29}$

\section{Advancement of Mastery-Based Learning}

The need for mastery-based learning was recognized in the original 1978 WHO report, but applying this educational approach has proven challenging. ${ }^{1}$ As noted above, it was a central tenet in the Toronto Orthopedics pilot. ${ }^{25}$ Substantial research has accumulated since the WHO report demonstrating the power of mastery-based learning and assessment to better prepare physicians and provide patients with higher quality and safer care. ${ }^{30}$ Masterybased learning requires a move away from the "see one, do one, teach one" mindset and arbitrary volumetrics around experience that lack supporting evidence. Mastery-based learning requires the learner do as much practice and assessment as required to meet a mastery standard of performance, including competencies beyond procedural skills. ${ }^{31}$ Medical interviewing, physical examination, and shared decision-making with patients are the core procedures of family medicine. Family medicine will need to shift from its traditional number metrics approach and adopt more mastery-based learning and assessment across multiple competencies. ${ }^{32}$ This is not to say volume of experience does not matter, but rather whatever volume of experience is required of the individual resident should be deliberately planned and delivered. This can be a daunting challenge for a field as broad and simultaneously deep as family medicine. The question for family medicine is what are the consequences of not moving in this direction, given the potentially negative implications for patients and communities as evidence accrues on the effectiveness of mastery-based approaches in generating better outcomes.

\section{Advances in Assessment}

CBME requires a robust, multifaceted program of assessment, often referred to as programmatic assessment, and is one of the five core components (Table 1). ${ }^{12,33}$ While traditional assessments such as 
knowledge examinations will remain an important part of programmatic assessment, family medicine will need to find the right combination of assessments to support the professional development of its residents and make summative entrustment decisions on behalf of the public. ${ }^{34}$ Better assessment approaches for the competencies of professionalism, practice-based learning and improvement, and systems-based practice are especially urgent.

This combination will need to increasingly include simulation (especially for procedural and communication competencies performed by family physicians), using masterybased standards, along with a combination of work-based assessments such as direct observation, multisource feedback, patient experience surveys, quality and safety measures, and assessment of clinical reasoning "in vivo." While much work remains to be done, an increasing number of tools and research have been developed and studied since the launch of the Outcome Project. ${ }^{8}$

Programs of assessment must also transition to a developmental, longitudinal mindset. Learning trajectories differ among residents, a fact acknowledged in the 1978 WHO report. Competency Milestones provide narratives that can serve as the core developmental assessment rubric that should guide the appropriate choice of assessment methods. Entrustable professional activities (EPAs) are another developmental assessment framework that can integrate needed physician abilities (aka competencies) in more holistic activities, such as care of patients with chronic disease, pregnancy, and so forth. ${ }^{35}$ Competency Milestones and EPAs are complementary and can help in the design of effective assessment programs.

Another important change in assessment was the introduction of clinical competency committees $(\mathrm{CCCs})$ concomitantly with the

Milestones. Group process, when done well, leads to better judgment, more robust feedback to residents, and ultimately better entrustment decisions. Effective CCCs synthesize assessment data to make valid developmental judgments that support learner development, help identify struggling learners earlier, and activate learners to coproduce their learning. ${ }^{37,38}$

Finally, the role of the resident in the assessment program requires rethinking. Residents must become active agents in the assessment process through coproduction. ${ }^{38,39}$ Coproduction in medical education can be defined as

\section{making better use of each other's assets, resources and contributions to achieve better [educational and clinical] outcomes or improve effi- ciency.}

Coproduction involves the interdependent work of learners, faculty, other health professionals, and patients that is intentionally and deliberately designed to contribute to the desired educational outcomes of learners and the desired health of individuals and populations. ${ }^{38}$ For too long assessment has been something GME programs do to residents instead of with them. Residents should be routinely seeking and performing assessments along with assessments completed by others. For example, residents should be empowered to ask to be directly observed with patients and engage in auditing their own medical records using quality and safety measures. ${ }^{39}$ They should, through coaching and conversation, review and synthesize their assessment data to create individualized learning plans. ${ }^{17,37}$ This is a major shift for residencies, but will be necessary to not only help ensure family medicine residency graduates are ready for unsupervised practice, but also prepare graduates for ongoing learning and growth toward expertise and mastery.

\section{Conclusions}

Residency training in family medicine, along with its partner specialties, has been on a 20-year journey to an outcomes-based educational model. The time has come to accelerate the pace of transformational change. This will not be easy, but family medicine can build on its leadership and rich traditions in developing training experiences in the ambulatory setting, incorporating behavioral health into training and patient care, and advancing the skills of practice management, to name just a few. ${ }^{40-42}$ Competencies are simply a vehicle, or framework, for defining the educational outcomes essential for effective clinical practice. Love them or hate them, the general competencies have forced all of us to attend to abilities beyond medical knowledge and patient care, such as interprofessional teamwork, quality improvement and patient safety, care coordination, and others. There is no question some of the newer competencies are harder to teach and assess, but that does not make them any less important. CBME is an approach to residency that incorporates a rich tapestry of pedagogical theories, approaches, and empiric research that remains a work-in-progress.

CBME should be continuously refined and informed by ongoing innovation and experimentation until the time a better model arises and can better meet the needs of patients and communities. Box 1 synthesizes some specific recommendations for family medicine to accelerate its shift to outcomes-based education. Ultimately, the GME community will need to demonstrate through rigorous research that $\mathrm{CBME}$ can produce both better educational and clinical care outcomes. Given its history, I have little doubt family medicine will be one of the leaders in this ongoing journey of transformation. 


\section{Box 1: Suggestions to Advance CBME in Family Medicine}

1. Using the core components framework, ${ }^{13}$ delineate the key curricular and programmatic assessment activities needed nationally in family medicine.

2. Support and advance multiinstitutional CBME pilots in family medicine building on past experience and success. ${ }^{42}$

3. Examine and research current assumptions about practice volumes using a developmental- and mastery-based mindset.

4. Implement mastery-based learning approaches in core clinical skills. ${ }^{2,30}$

5. Embrace coproduction as a strategy and educational tool to advance CBME. ${ }^{38}$

6. Work collaboratively within family medicine and with other disciplines to develop and implement new assessment approaches in professionalism, practice-based learning and improvement, and systems-based practice. ${ }^{34,43}$

7. Create a family medicine-specific blueprint for programmatic assessment all residency programs can leverage to improve assessment practices.

8. Invest in the faculty training necessary to improve faculty's own abilities in key clinical competences, feedback, and coaching. ${ }^{10,17,34,43}$

Abbreviation: CBME, competency-based medical education.

DISCLOSURE: The author receives royalties from Elsevier for the textbook Practical Guide to the Evaluation of Clinical Competence, 2nd Edition.

CORRESPONDENCE: Address correspondence to Dr Eric S. Holmboe, Chief Research, Milestones Development and Evaluation Officer, Accreditation Council for Graduate Medical Education, 401 North Michigan Avenue, Chicago, IL 60611. 312-755-7034. eholmboe@acgme.org.

\section{References}

1. McGaghie WC, Miller GE, Sajid AW, Telder TV. Competency-based curriculum development in medical education. Public Health Paper No. 68. Geneva, Switzerland: World Health Organization; 1978.

2. McGaghie WC, Barsuk JH, Wayne DB. Clinical Education: origins and Outcomes. In: McGaghie WC, Barsuk JH, Wayne DB, eds. Comprehensive Healthcare Simulation: Mastery Learning in Health Professions Education. Cham, Switzerland: Springer Nature; 2020. doi:10.1007/978-3-030-34811-3_1

3. Holmboe ES, Batalden P. Achieving the desired transformation: thoughts on next steps for outcomes-based medical education. Acad Med. 2015;90(9):1215-1223. doi:10.1097/ ACM.0000000000000779

4. Kohn LT, Corrigan J, Donaldson MS. To Err Is Human: Building a Safer Health System. Washington, DC: National Academy Press; 2000 .

5. Institute of Medicine, Committee on Quality of Health Care in America. Crossing the quality chasms: a new health system for the 21st century. Washington: National Academy Press; 2001.

6. James JT. A new, evidence-based estimate of patient harms associated with hospital care. J Patient Saf. 2013;9(3):122-128. doi:10.1097/ PTS.0b013e3182948a69

7. McGlynn EA, Asch SM, Adams J, Keesey J, Hicks J, DeCristofaro A, Kerr EA. The quality of health care delivered to adults in the United States. 2003; 348(26): 2635-45. doi:10.1056/ NEJMsa022615
8. Batalden P, Leach D, Swing S, Dreyfus H Dreyfus S. General competencies and accreditation in graduate medical education. Health Aff (Millwood). 2002;21(5):103-111. doi:10.1377/ hlthaff.21.5.103

9. Hodges BD. A tea-steeping or i-Doc model for medical education? Acad Med. 2010;85(9)(suppl):S34-S44. doi:10.1097/ ACM.0b013e3181f12f32

10. Wong BM, Holmboe ES. Transforming academic faculty to better align educational and clinical outcomes. Acad Med. 2016;91(4):473479. doi:10.1097/ACM.0000000000001035

11. Thibault GE. The future of health professions education: emerging trends in the United States. FASEB Bioadv. 2020;2(12):685-694. doi:10.1096/fba.2020-00061

12. Frank JR, Snell LS, Cate OT, et al. Competency-based medical education: theory to practice. Med Teach. 2010;32(8):638-645. doi:10.3109/01 42159X.2010.501190

13. Van Melle E, Frank JR, Holmboe ES, Dagnone D, Stockley D, Sherbino J; International Competency-based Medical Education Collaborators. A core components framework for evaluating implementation of competencybased medical education programs. Acad Med. 2019;94(7):1002-1009. doi:10.1097/ ACM.0000000000002743

14. Govaerts MJB, van der Vleuten CPM, Holmboe ES. Managing tensions in assessment moving beyond either-or thinking. Med Educ. 2019;53(1):64-75. doi:10.1111/medu.13656

15. Ericsson KA. An expert-performance perspective of research on medical expertise: the study of clinical performance. Med Educ. 2007;41(12):1124-1130. doi:10.1111/j.1365 2923.2007.02946.x

16. Ericsson KA, Pool R. Peak: secrets from the new science of expertise. Boston: Houghton Mifflin Harcourt; 2016.

17. Deiorio NM, Skye E, Sheu L. Introduction and definition of academic coaching. In: Coaching in Medical Education. A faculty Handbook. American Medical Association; 2017:chap 1.

18. Dreyfus HL, Dreyfus SE. Mind over machine: the power of human intuition and expertise in the era of the computer. New York: Free Press; 1986.
19. Green ML, Aagaard EM, Caverzagie KJ, et al. Charting the road to competence: developmental milestones for internal medicine residency training. J Grad Med Educ. 2009;1(1):5-20. doi:10.4300/01.01.0003

20. Nasca T., Philibert I, Brigham T, Flynn TC. The next GME accreditation system-rationale and benefits. N Engl J Med. 2012;366(11):10511056. doi:10.1056/NEJMsr1200117

21. Accreditation Council for Graduate Medical Education. ACGME Family Medicine Milestones. https://www.acgme.org/Portals/0/ PDFs/Milestones/FamilyMedicineMilestones. pdf?ver=2020-09-01-150203-400. Revised October 2018. Accessed November 19, 2020.

22. Peabody MR, O'Neill TR, Peterson LE. Examining the Functioning and Reliability of the Family Medicine Milestones. J Grad Med Educ. 2017;9(1):46-53. doi:10.4300/JGMED-16-00172.1

23. Yaghmour NA, Poulin LJ, Bernabeo EC, et al. Stages of milestones implementation: a template analysis of 16 programs across four specialties. J Grad Med Educ. In press.

24. Brydges R, Boyd VA, Tavares W, et al. Assumptions about competency-based medical education and the state of the underlying evidence: a critical narrative review. Acad Med. 2021;96(2):296-306.

25. Nousiainen MT, Caverzagie KJ, Ferguson PC, Frank JR, Collaborators ICBME; ICBME Collaborators. Implementing competency-based medical education: what changes in curricular structure and processes are needed? Med Teach. 2017;39(6):594-598. doi:10.1080/014215 9X.2017.1315077

26. Andrews JS, Bale JF Jr, Soep JB, et al; EPAC Study Group. Education in Pediatrics Across the Continuum (EPAC): First Steps Toward Realizing the Dream of Competency-Based Education. Acad Med. 2018;93(3):414-420. doi:10.1097/ACM.0000000000002020

27. Murray KE, Lane JL, Carraccio C, et al; Education in Pediatrics Across the Continuum (EPAC) Study Group. Crossing the gap: using competency-based assessment to determine whether learners are ready for the undergraduate-to-graduate transition. Acad Med. 2019;94(3):338-345. doi:10.1097/ ACM.0000000000002535 
28. Hall AK, Rich J, Dagnone JD, et al. It's a Marathon, Not a Sprint: Rapid Evaluation of Competency-Based Medical Education Program Implementation. Acad Med. 2020;95(5):786793. doi:10.1097/ACM.0000000000003040

29. Lucey CR, Thibault GE, Ten Cate O. Competency-based, time-variable education in the health professions; Crossroads. Acad Med. 2018;93(3S Competency-Based, Time-Variable Education in the Health Professions):S1-S5. doi:10.1097/ACM.0000000000002080

30. McGaghie WC, Barsuk JH, Wayne DB. The promise and challenge of mastery learning. Adv Med Educ Pract. 2017;8:393-394. doi:10.2147/AMEP.S141073

31. Salzman DH, McGaghie WC, Caprio TW, et al. A mastery learning capstone course to teach and assess components of three entrustable professional activities to graduating medical students. Teach Learn Med. 2019;31(2):186194. doi:10.1080/10401334.2018.1526689

32. Accreditation Council for Graduate Medical Education. ACGME Program Requirements for Graduate Medical Education in Family Medicine. https://www.acgme.org/Portals/0/PFAssets/ProgramRequirements/120_FamilyMedicine_2020.pdf Accessed November 21, 2020.

33. van der Vleuten CP, Schuwirth LW, Driessen EW, et al. A model for programmatic assessment fit for purpose. Med Teach. 2012;34(3):205-214. doi:10.3109/014215 9X.2012.652239
34. Holmboe ES, Iobst WI. The Assessment Guidebook. Chicago: ACGME; 2020 https:/ www.acgme.org/Portals/0/PDFs/Milestones/Guidebooks/AssessmentGuidebook. pdf?ver=2020-11-18-155141-527. Accessed February 5, 2021.

35. Ten Cate O. Nuts and bolts of entrustable professional activities. J Grad Med Educ. 2013;5(1):157-158. doi:10.4300/JGME D-12-00380.1

36. Carraccio C, Englander R, Gilhooly J, et al. Building a framework of entrustable professional activities, supported by competencies and milestones, to build a bridge the educational continuum. Acad Med. 2017;92(3):324330. doi:10.1097/ACM.0000000000001141

37. Andolsek K, Padmore J, Hauer KE, Edgar L, Holmboe E. Clinical Competency Committees. A Guidebook for Programs. 3rd edition. Chicago: ACGME; 2020. https://www.acgme.org/ Portals/0/ACGMEClinicalCompetencyCommitteeGuidebook.pdf?ver=2020-04-16-121941-380 Accessed November 19, 2020.

38. Englander R, Holmboe E, Batalden P, et al Coproducing health professions education: A requisite to coproducing health care service? Acad Med. 2020;95(7):1006-1013. doi:10.1097/ ACM.0000000000003137

39. Holmboe ES. Work-based assessment and co-production in postgraduate medical training. GMS J Med Educ. 2017;34(5):Doc58. doi:10.3205/zma001135
40. Gutierrez C and Schied P. The History of Family Medicine and Its Impact in US Health Care Delivery. https://www.aafpfoundation.org/content/dam/foundation/documents/who-we-are/ $\mathrm{cfhm} / \mathrm{FMImpactGutierrezScheid.pdf.} \mathrm{Accessed}$ November 18, 2020.

41. Phillips RL Jr, Pugno PA, Saultz JW, et al. Health is primary: family medicine for America's health. Ann Fam Med. 2014;12(suppl 1):S1S12. doi:10.1370/afm.1699

42. Green LA, Jones SM, Fetter G Jr, Pugno PA. Preparing the personal physician for practice: changing family medicine residency training to enable new model practice. Acad Med. 2007;82(12):1220-1227. doi:10.1097/ ACM.0b013e318159d070

43. Family Medicine Milestones 2.0 Working Group. Supplemental Guide: Family Medicine. https://www.acgme.org/Portals/0/PDFs/Milestones/FamilyMedicineSupplementalGuide. pdf?ver=2019-12-13-091243-987. Published October 2019. Accessed February 5, 2021. 